\title{
OPTIMALISASI FACE RIGGING PADA PEMBUATAN KARAKTER ANIMASI 3D
}

\author{
Ismail Abdurrozzaq Zulkarnain ${ }^{1}$, Khoiru Nurfitri ${ }^{2}$, Nurwanto ${ }^{3}$ \\ 1,2,3 Universtas Muhammadiyah Ponorogo
}

\section{Article Info:}

Dikirim: 24 September 2019

Direvisi: 24 Desember 2019

Diterima: 31 Desember 2019

Tersedia Online: 31 Desember 2019

Penulis Korespondensi:

Ismail Abdurrozzaq Z

Universitas Muhammadiyah

Ponorogo, Jawa Timur, Indonesia

Email: iizzuel@gmail.com

\begin{abstract}
Abstrak: Penelitian ini bertujuan untuk mempermudah dalam pembuatan rigging khususnya yang ada pada wajah dari sebuah karakter 3D. Pada karakter 3D khususnya karakter manusia, agar terlihat lebih nyata dan sesuai dengan manusia aslinya, maka wajah perlu diberikan struktur penulangan agar setiap komponen dari wajah tersebut dapat bergerak sesuai dengan gerakan wajah. Mimik dari sebuah wajah tentunya akan berbeda ketika karakter tersebut mendapatkan suatu ekspresi tertentu, bisa marah, sedih, senang, resah, kecewa, kaget, dan sebagainya. Antara mata, hidung, alis, mulut akan bergerak sesuai ekspresi yang dihasilkan oleh wajah tersebut. Pada film animasi atau game animasi mimik wajah sangatlah menentukan ekspresi dari suatu karakter tersebut. Sehingga dengan munculnya mimik wajah akan membuat suatu film animasi atau game animasi terlihat lebih nyata. Dengan metode research and development penelitian ini menghasilkan simulasi rigging pada wajah karakter manusia $3 D$ sehingga didapatkan mimik wajah yang sesuai dengan aslinya. Metode pengujian pada simulasi ini adalah tingkat kemiripan dari gerakan wajah manusia asli dengan gerakan wajah karakter 3D yang telah diberi komponen rig didalamnya. Gerakan - gerakan yang dihasilkan oleh setiap ekspresi wajah merupakan hasil gerakan dari komponen wajah yang saling berhubungan.
\end{abstract}

Kata kunci: 3 dimensi; rigging; optimalisasi.

\begin{abstract}
This study aims to facilitate the making of rigging, especially those on the face of a $3 D$ character. In $3 D$ characters, especially human characters, to make it look more real and in accordance with the original human, then the face needs to be given a reinforcement structure so that each component of the face can move according to facial movements. The face of a face will certainly be different when the character gets a certain expression, can be angry, sad, happy, restless, disappointed, shocked, and so on. Between the eyes, nose, eyebrows, mouth will move according to the expression produced by the face. In animated films or facial animation games are very determining the expression of a character. So that with the appearance of facial expressions will make an animated film or animated game look more real. With the research and development method, this research produces rigging simulations on the faces of $3 D$ human characters so that facial expressions are in accordance with the originals. The testing method in this simulation is the degree of similarity of the original human face movements with the face movements of $3 D$ characters that have been given a rig component in it. The movements produced by each facial expression are the result of movements of interconnected facial components.
\end{abstract}

Keywords: 3-dimension; rigging; optimalization. 


\section{PENDAHULUAN}

Film animasi sudah banyak digunakan masyarakat untuk berbagai tujuan dalam pendidikan, ekonomi, sosial, bahkan industri hiburan. Bahwasannya film animasi adalah salah satu cara paling efektif untuk membuat sesuatu hal menjadi menarik. Dengan animasi pembelajaran yang tadinya monoton akan menjadi lebih interaktif dan menarik. Dalam hal ekonomi animasi menjadi pendukung di bidang publikasi suatu produk atau jasa, dengan animasi barang tersebut akan banyak diminati pasar.

Saat ini anggapan masyarakat tentang animasi bahwasanya yang membuat animasi mulai dari modeling sampai compositing adalah animator, namun sebenarnya ada bagian lain yang bertugas untuk membuat model animasi, memberikan tekstur, memberikan rig animasi, hingga menggerakkan model tersebut. Oleh karena itu dari suatu studio animasi terdapat beberapa bagian atau divisi sesuai dengan tahapan pembuatan animasi tersebut, mulai modelling, rigging, texturing, lighting, animation, composition.

Menurut Aditya (2009) dalam pembuatan animasi 3D terdapat proses yang disebut rigging. Rigging adalah metode pemberian atau pemasangan tulang pada karakter animasi agar bisa digerakkan. Sehingga karakter dapat bergerak seperti manusia atau makhluk hidup lain. Salah satu fungsi animasi yaitu dapat berinteraktif antara bidang multimedia dengan masyarakat umumnya. Dengan menggunakan media animasi orang lebih tertarik dan terhibur saat mendapatkan informasi. Di dalam animasi banyak ekspresi wajah yang disampaikan menyerupai bentuk wajah manusia pada aslinya. Namun animasi memiliki bentuk ekspresi wajah yang lebih menarik, lucu dan berkarakter.

Penelitian yang dilakukan oleh Nimas Arum (2012), yang berjudul Modelling dan Rigging Karakter Animasi 3 Dimensi Tentang Proses Pembuatan Tempe. Pada penelitian tersebut rigging hanya dilakukan pada bagian kepala dan badan tidak sampai wajah pada karakter 3 dimensi. Sedangkan pada penelitian yang dilakukan oleh Aski Satriawan dan Meyti Eka Apriyani (2016), yang berjudul Analisa dan Pembuatan Rigging Karakter 3D pada animasi 3D “Jangan Bohong Dong". Pada penelitian tersebut pemodelan hingga proses rigging dilakukan pada sau aplikasi dan proses rigging hanya pada kepala, badan, tangan, dan kaki. Pada wajah tidak diberikan optimalisasi rigging sehingga ekspresi karakter tidak mirip dengan wajah manusia asli.

Ekspresi pada wajah dapat menggambarkan suatu kepribadian dan perasaan dari karakter tersebut, namun kadang para animator pemula sulit menggambarkan atau membentuk dari mimik wajah karakter. Sehingga animasi yang dihasilkan tidak mirip dengan aslinya. Keterkaitan hubungan antara beberapa komponen pada wajah, dapat menghasilkan pola dimana pola tersebut menjadi ekspresi yang dihasilkan oleh setiap wajah.

\section{METODOLOGI PENELITIAN}

Proses pengumpulan data dilakukan dengan metode studi pustaka, baik dari artikel jurnal, buku, maupun yang ada di internet. Data - data yang didapatkan kemudian dilakukan pengeskploran dengan beragam pertimbangan baik dari segi waktu penelitian maupun biaya implementasi. Hasil yang diharapkan nantinya berupa hasil uji coba dari sebuah hipotesis yang telah teruji dan mempunyai nilai tepat guna bagi masyarakat Indonesia. Penelitian terdahulu juga dilakukan melalui pengujian - pengujian eksperimentatif mendasar tentang perkiraan capaian yang dimungkinkan. Secara umum proses penelitian dan pencapaian hasil akhir akan dilakukan dengan metode yang sama seperti di atas yaitu metode penelitian eksploratif eksperimentatif.

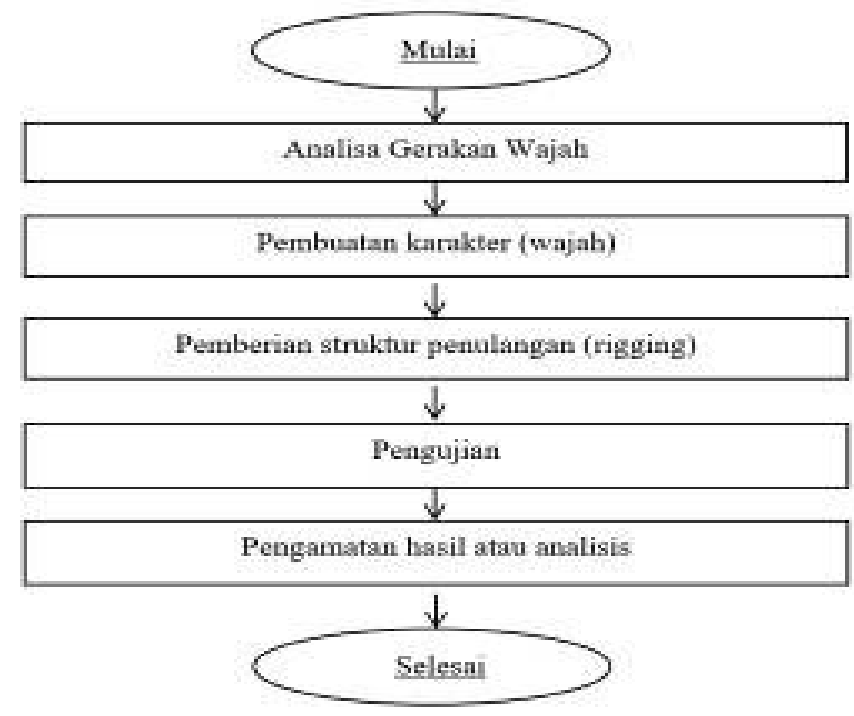

Gambar 2. Alur Penelitian 
Dari alur penelitian di atas dapat dijabarkan sebagai berikut:

1) Analisa gerak wajah, dilakukan dengan melakukan Analisa terhadap beberapa video rekaman tentang gerak wajah, mulai dari kepala, alis, mata, dan mulut.

2) Pembuatan karakter wajah sesuai dengan wajah manusia yang berbentuk animasi 3D dimana wajah yang dibuat sesuai dengan tata letak bagian-bagian dari wajah manusia aslinya.

3) Pemberian struktur penulangan dari wajah dilakukan dengan cara memberikan rig sesuai dengan hasil Analisa gerakan wajah.

4) Pengujian dilakukan dengan cara menggerakkan karakter sesuai dengan gerakan pada wajah manusia, kemudian dilihat tingkat kemiripan dari karakter animasi tersebut dengan aslinya.

Pengamatan hasil dan analisis, setelah semua diuji coba maka dilakukan pengamatan dan analisis hasil yang akan didapat dan menentukan gerakan wajah dari karakter animasi 3D

\section{HASIL DAN PEMBAHASAN}

\subsection{Analisa Gerak Wajah}

Pada tahap ini peneliti melakukan capture wajah manusia dengan menggunakan kamera DSLR. Proses rekaman wajah yang dilakukan meliputi pergerakan alis, mata, pipi, dan mulut. Sebelum melakukan perekaman, wajah pada objek manusia diberi tanda titik terlebih dahulu agar mudah menetukan arah dan sudut gerakan seperti yang ditunjukkan pada gambar 3 dan 4.

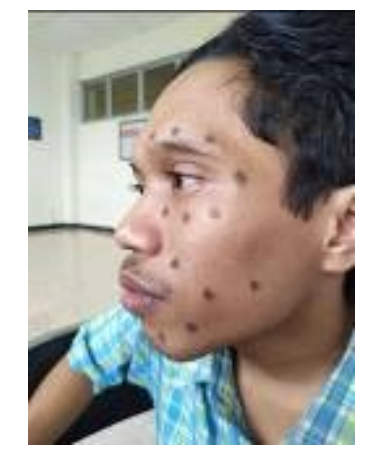

\section{Gambar 3. Titik-Titik Gerak Dilihat Dari Samping}

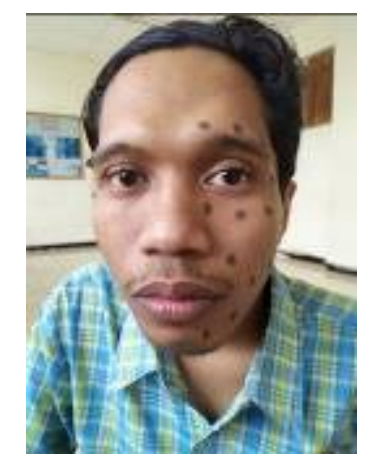

Gambar 4. Titik-Titik Gerak Dilihat Dari Depan

\subsection{Pembuatan Karakter Wajah 3D}

Dalam pembuatan karakter wajah 3D seperti yang ditunjukkan pada gambar 5, peneliti menggunakan software Autodesk Maya 2017. Tahapan Pembuatan karakter meliputi:

1) Tahapan dimulai dari pembuatan objek bola (sphere)

2) Pembentukan struktur bentuk wajah

3) Pembentukan kelopak mata dan bola mata

4) Pembentukan hidung

5) Pembentukan struktur pipi

6) Pembentukan mulut (bibir atas dan bawah)

7) Pembentukan dagu 


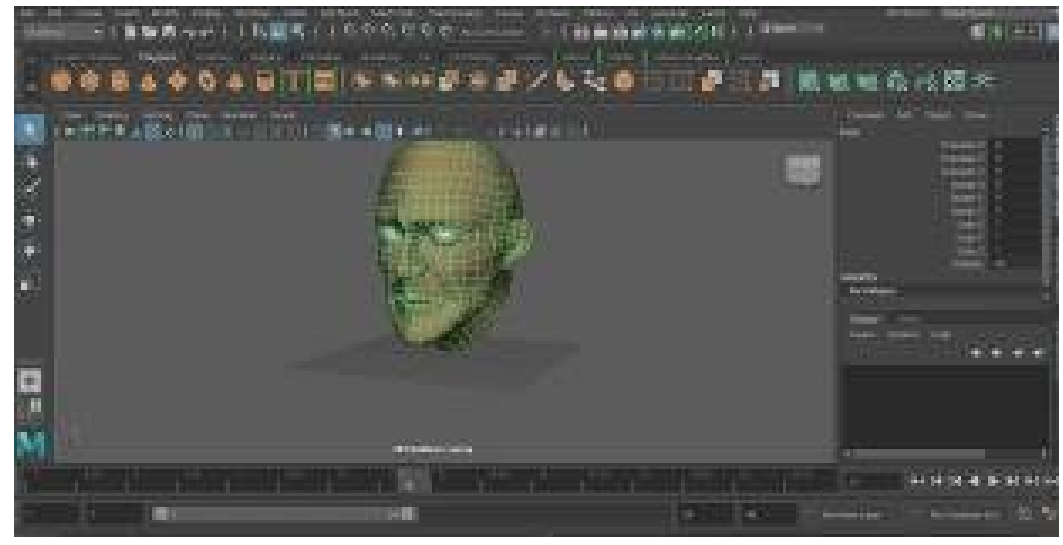

Gambar 5. Karakter Wajah 3D

\subsection{Pemberian Struktur Penulangan (Rigging)}

1) Pembentukan struktur pusat rigging, mulai dari bawah kepala (terusan leher), hingga tepat atas kepala seperti yang ditunjukkan pada gambar 6 .

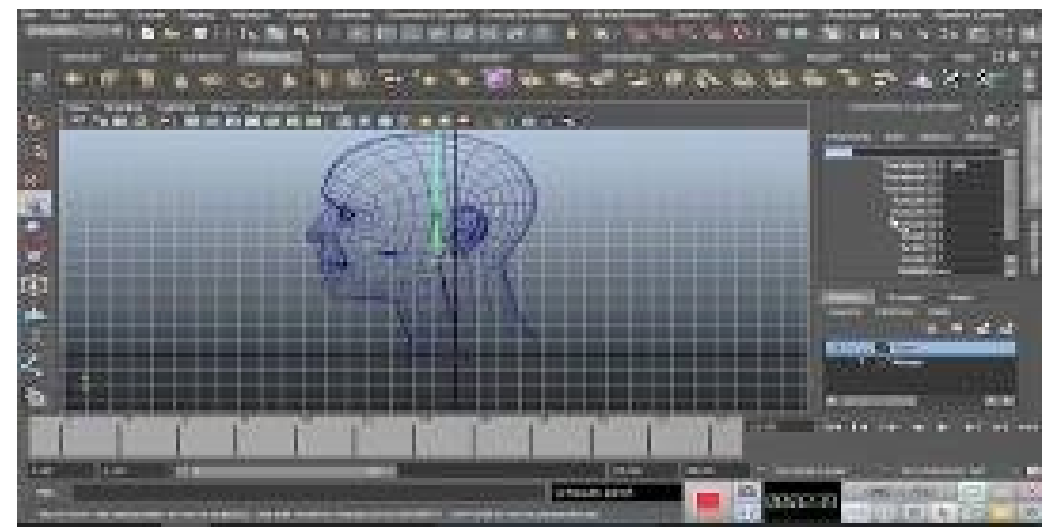

Gambar 6. Struktur Pusat Rigging

2) Pembentukan terusan rig dari pusat rigging menuju bawah bibir bagian bawah seperti yang ditunjukkan pada gambar 7.

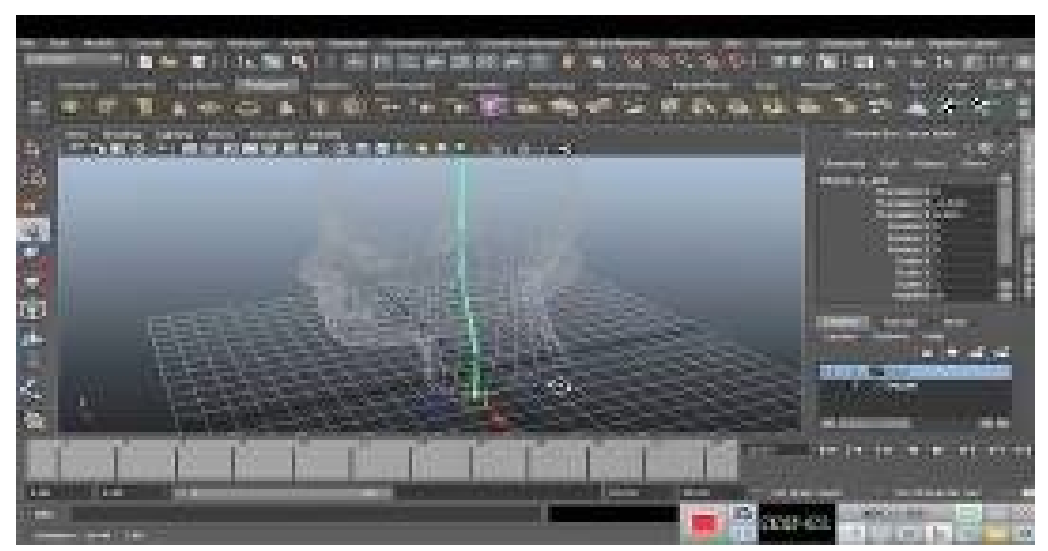

Gambar 7. Terusan Dari Pusat Rigging 
3) Pembentukan titik-titik gerakan pada alis kanan dan kiri seperti yang ditunjukkan pada gambar 8 .

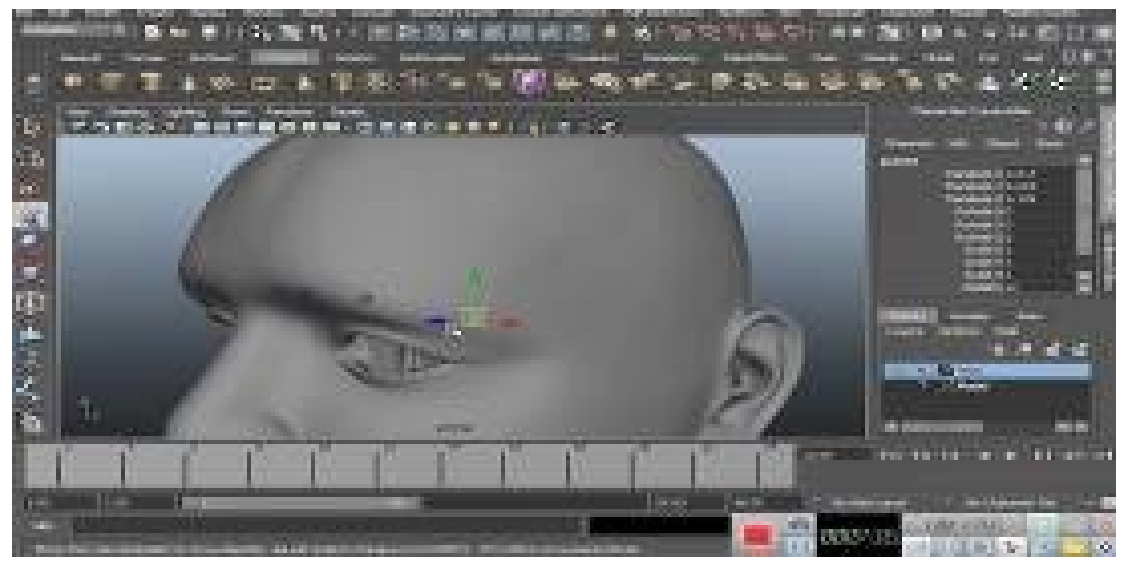

Gambar 8. Titik Gerakan Alis

4) Pembentukan titik-titik gerakan pada pipi kanan dan kiri seperti yang ditunjukkan pada gambar 9.

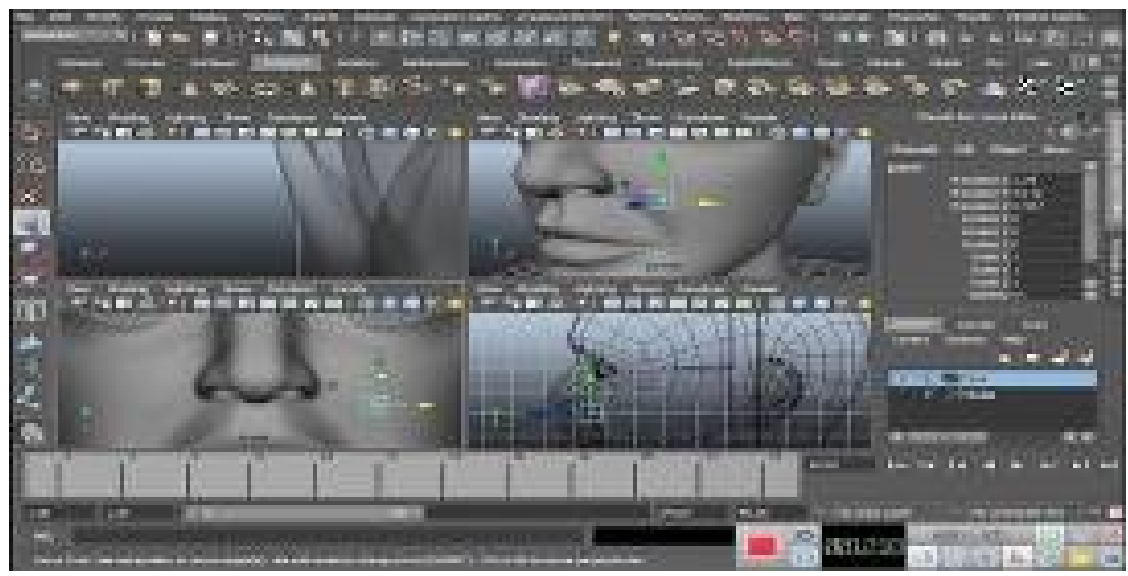

\section{Gambar 9. Titik Gerakan Pipi}

5) Pembentukan titik-titik gerakan pada pipi bawah kanan dan kiri seperti yang ditunjukkan pada gambar 10.

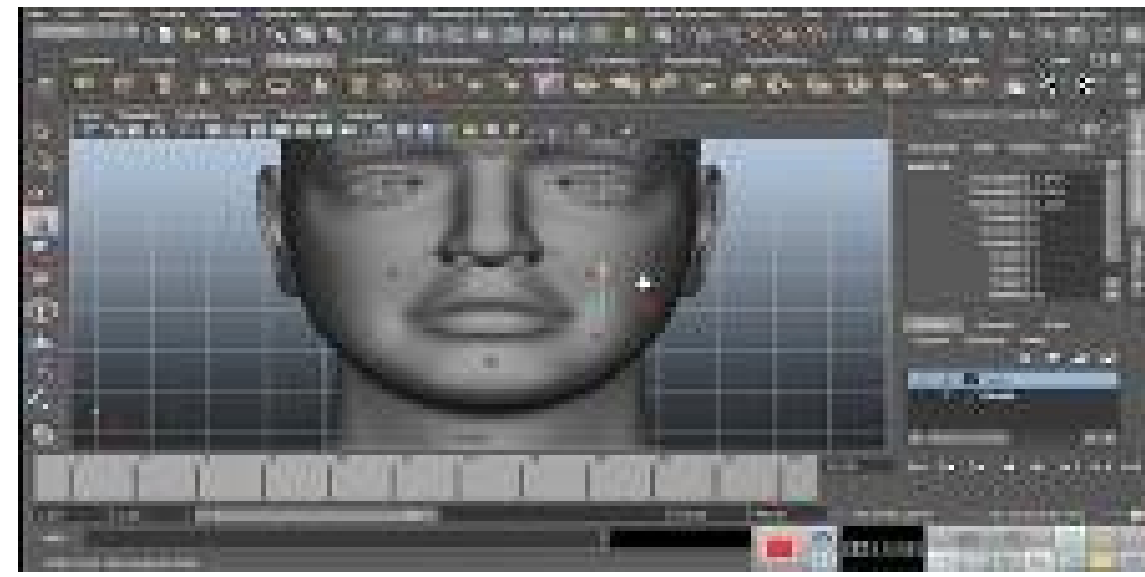

Gambar 10. Titik Gerakan Pipi Bawah 
6) Pembentukan titik-titik gerakan pada bawah kelopak mata seperti yang ditunjukkan pada gambar 11.

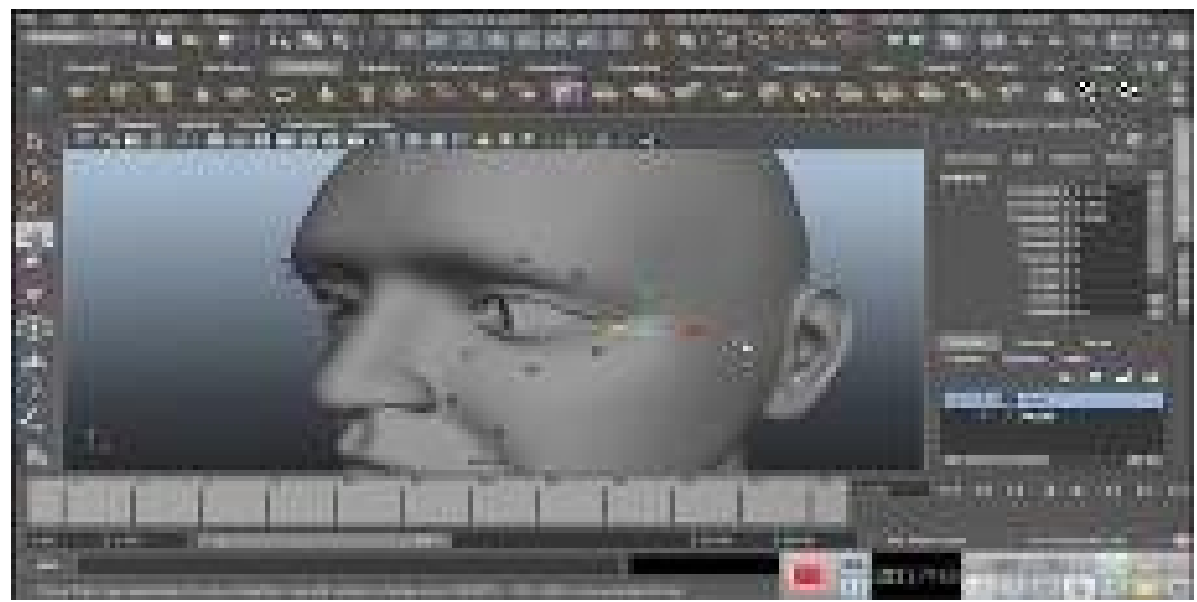

\section{Gambar 11. Titik Gerakan Kelopak Mata}

7) Menyatukan semua titik gerakan ke pusat rig kepala seperti yang ditunjukkan pada gambar 12.

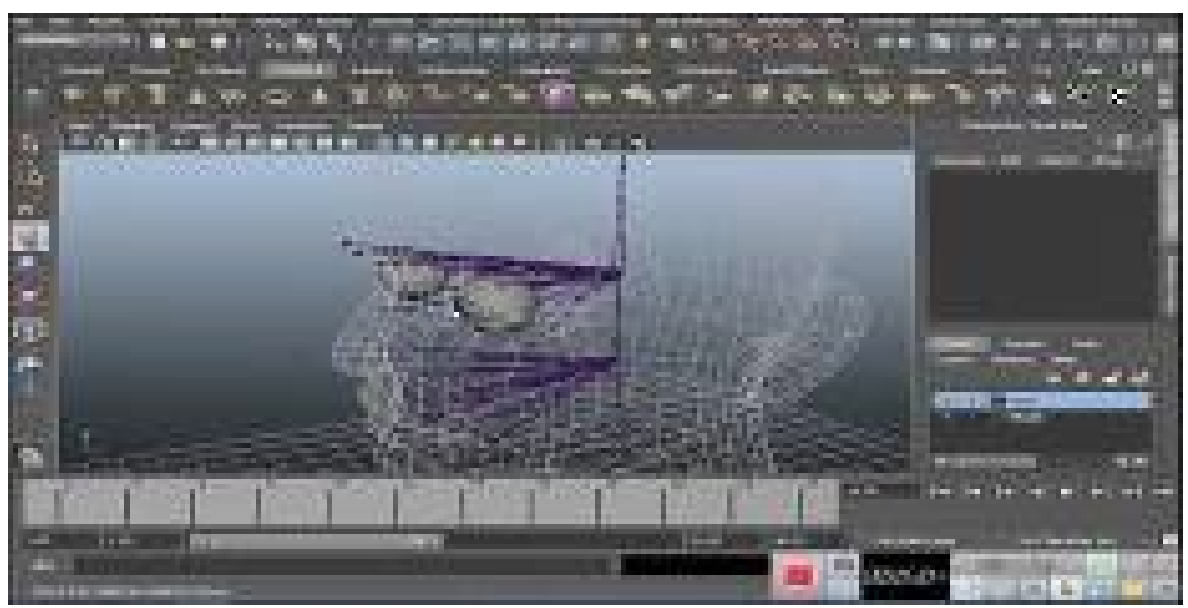

\section{Gambar 12. Terusan Titik Gerakan Ke Pusat Rigging}

8) Memberikan 3D Axis untuk gerakan disetiap titik-titik gerakan seperti yang ditunjukkan pada gambar 13.

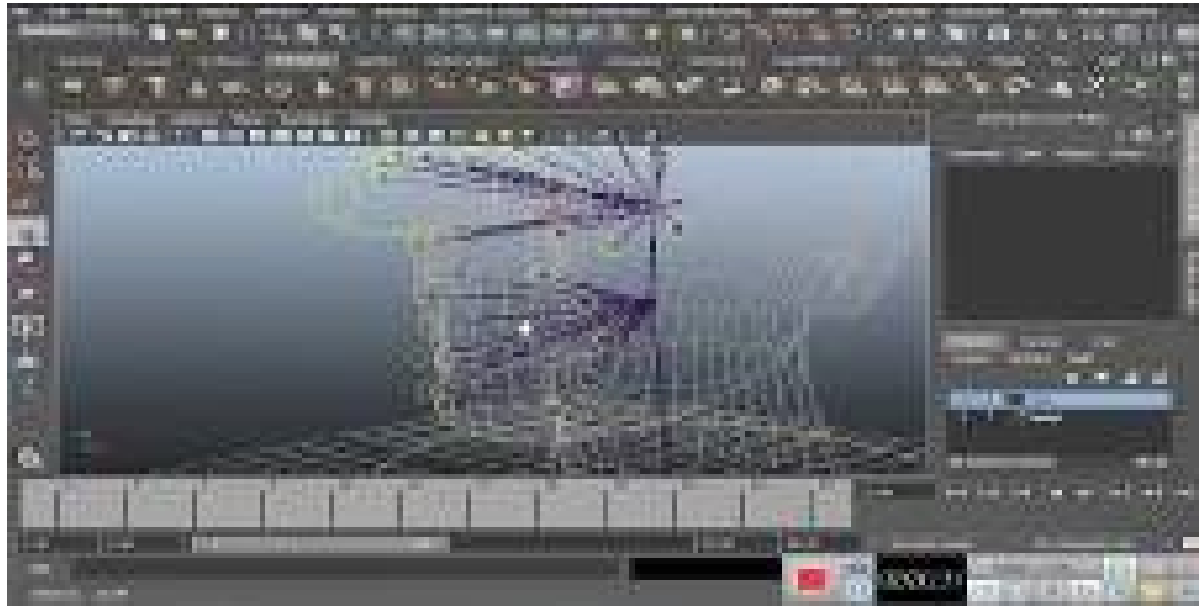

Gambar 13. 3D Axis Pada Titik Gerakan 
9) Memberikan mesh area gerakan disekitar titik-titik gerakan seperti yang ditunjukkan pada gambar 14.

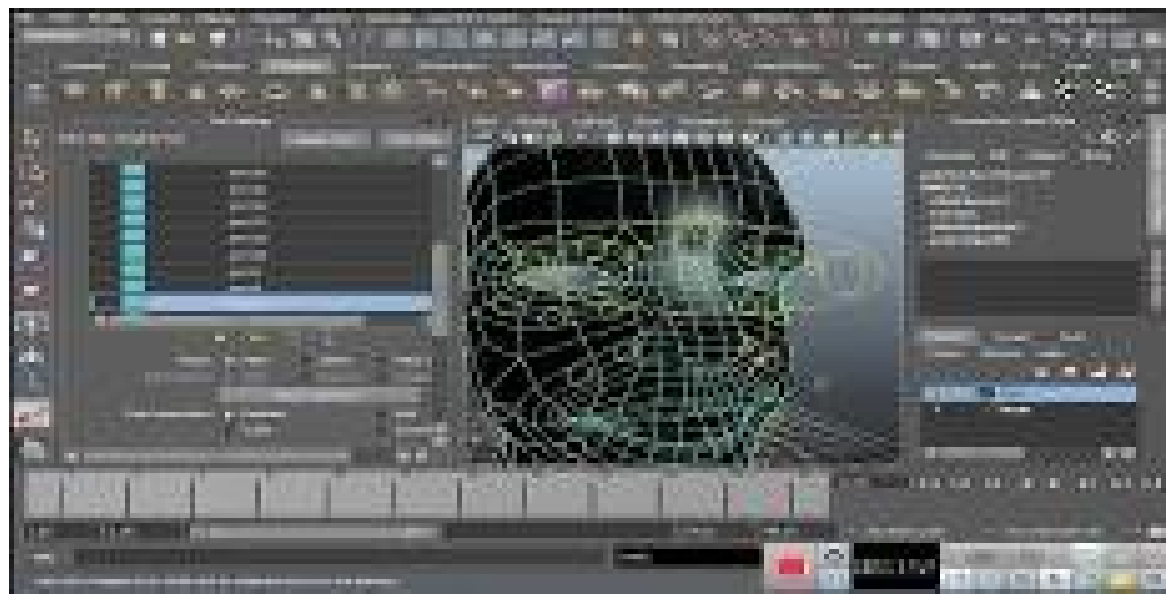

\section{Gambar 14. Mesh Area Titik Gerakan}

10) Optimalisasi gerakan disetiap titik-titik gerakan seperti yang ditunjukkan pada gambar 15.

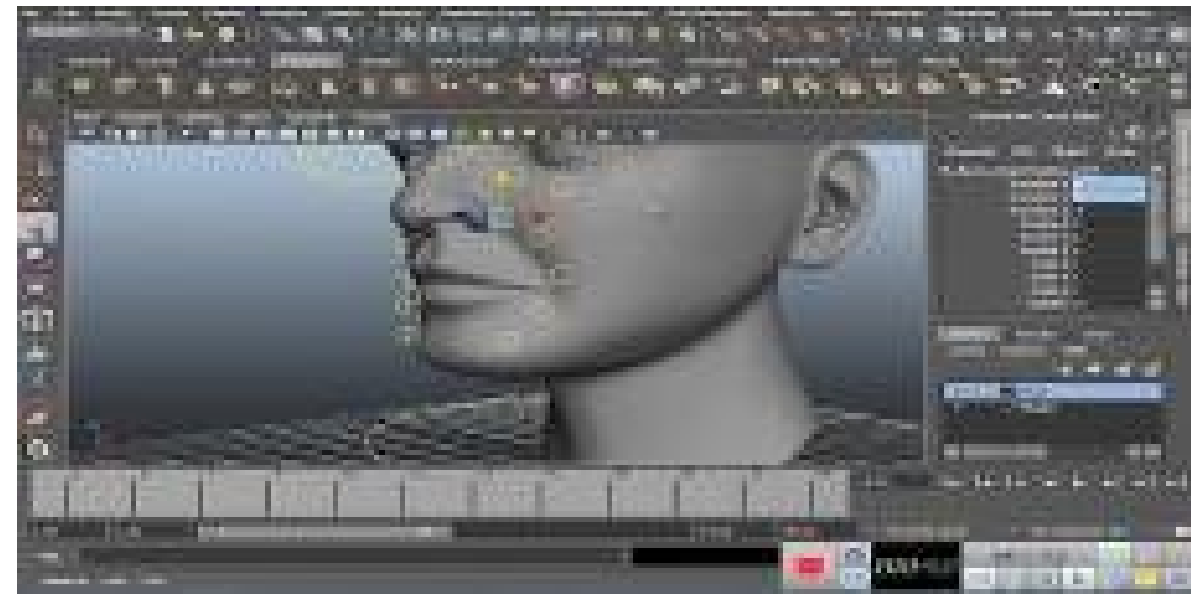

Gambar 15. Optimalisasi Titik Gerakan

11) Optimalisasi Gerakan

Pada dasarnya untuk dapat menciptakan ekspresi wajah dari karakter animasi, optimalisasi masing-masing dari titik-titik sudut struktur penulangan antara struktur satu dengan struktur yang lain sangatlah penting. Karena untuk menghasilkan satu ekspresi wajah dapat menggerakkan 5 sampai 10 titik dari sudut rigging yang telah dibuat. Misalkan untuk menghasilkan ekspresi mata melotot dapat menggerakkan 10 titik ujung rigging dari struktur penulangan bagian mata bagian kanan dan 10 titik sudut rigging bagian kiri.

Dalam pembuatan wajah karakter animasi 3D, seringnya animator hanya membuat rigging terhenti pada titik kepala dan leher saja, sehingga yang dapat digerakkan hanya satu bagian kepala saja. Dengan mengoptimalkan banyak titik rigging dari wajah karakter 3D akan dapat menghasilkan wajah karakter yang ekspresif. Mulai titik rigging bagian mata, hidung, pipi, mulut dan dagu. Jika kelima bagian tersebut dapat dioptimalkan titik rigging-nya, akan dapat menghasilkan wajah karakter yang ekspresif dan inspiratif.

\section{KESIMPULAN}

Pengujian dilakukan dengan pengamatan tingkat kemiripan yang dihasilkan oleh karakter animasi 3D dengan wajah manusia asli. Penghitungan dari besar sudut dan jarak antara titik rigging yang sudah diberikan pada wajah manusia asli dengan titik rigging pada wajah karakter animasi 3D. 
Tabel 1. Perbandingan tingkat kemiripan wajah manusia dengan karakter animasi 3D

\begin{tabular}{|c|c|c|c|c|c|c|c|c|c|c|}
\hline \multicolumn{10}{|c|}{ PERGERAKAN } & \multirow{3}{*}{$\begin{array}{c}\text { Tingkat } \\
\text { kemiripan } \\
(\%)\end{array}$} \\
\hline \multicolumn{5}{|c|}{ Wajah Manusia } & \multicolumn{5}{|c|}{ Wajah Karakter 3D } & \\
\hline Mata & Hidung & Pipi & Bibir & Dagu & Mata & Hidung & Pipi & Bibir & Dagu & \\
\hline Atas & Atas & Atas & Atas & Atas & Atas & Atas & Atas & Atas & Atas & \\
\hline $4,5 \mathrm{~mm}$ & $0.7 \mathrm{~mm}$ & $3,8 \mathrm{~mm}$ & $8 \mathrm{~mm}$ & $5 \mathrm{~mm}$ & $5 \mathrm{~mm}$ & $2 \mathrm{~mm}$ & $4 \mathrm{~mm}$ & $10 \mathrm{~mm}$ & $5 \mathrm{~mm}$ & $90 \%$ \\
\hline $90^{\circ}$ & $85^{\circ}$ & $82^{\circ}$ & $90^{\circ}$ & $90^{\circ}$ & $90^{\circ}$ & $90^{\circ}$ & $90^{\circ}$ & $90^{\circ}$ & $90^{\circ}$ & \\
\hline Bawah & Bawah & Bawah & Bawah & Bawah & Bawah & Bawah & Bawah & Bawah & Bawah & \\
\hline $4,5 \mathrm{~mm}$ & $0.3 \mathrm{~mm}$ & $0.3 \mathrm{~mm}$ & $3 \mathrm{~mm}$ & $3,7 \mathrm{~mm}$ & $5 \mathrm{~mm}$ & $2 \mathrm{~mm}$ & $2 \mathrm{~mm}$ & $5 \mathrm{~mm}$ & $5 \mathrm{~mm}$ & $90 \%$ \\
\hline $90^{\circ}$ & $87^{\circ}$ & $83^{\circ}$ & $87^{\circ}$ & $90^{\circ}$ & $90^{\circ}$ & $90^{\circ}$ & $90^{\circ}$ & $90^{\circ}$ & $90^{\circ}$ & \\
\hline Kanan & & & Kanan & Kanan & Kanan & & & Kanan & Kanan & \\
\hline $4,7 \mathrm{~mm}$ & - & - & $4,7 \mathrm{~mm}$ & $3,2 \mathrm{~mm}$ & $5 \mathrm{~mm}$ & - & - & $5 \mathrm{~mm}$ & $5 \mathrm{~mm}$ & $64 \%$ \\
\hline $180^{\circ}$ & & & $173^{\circ}$ & $172^{\circ}$ & $180^{\circ}$ & & & $180^{\circ}$ & $180^{\circ}$ & \\
\hline Kiri & & & Kiri & Kiri & Kiri & & & Kiri & Kiri & \\
\hline $4,7 \mathrm{~mm}$ & - & - & $4,7 \mathrm{~mm}$ & $3,2 \mathrm{~mm}$ & $5 \mathrm{~mm}$ & - & - & $5 \mathrm{~mm}$ & $5 \mathrm{~mm}$ & $64 \%$ \\
\hline $180^{\circ}$ & & & $173^{\circ}$ & $172^{\circ}$ & $180^{\circ}$ & & & $180^{\circ}$ & $180^{\circ}$ & \\
\hline
\end{tabular}

Dari hasil tabel diatas dihasilkan bahwasannya rata-rata tingkat kemiripan yang dihasilkan oleh wajah manusia asli dan wajah karakter animasi 3D adalah 70\% sehingga dapat dinyatakan bahwa dengan optimalisasi dari masing-masing titik rigging pada wajah akan menghasilkan kemiripan dari wajah karakter 3D dengan wajah manusia asli.

Pada karakter wajah yang tidak diberikan titik-titik gerakan pada setiap tempat titik tersebut, akan sulit membuat gerakan wajah sesuai dengan wajah asli manusia dimana wajah asli manusia dapat menggambarkan berbagai macam mimik, antara lain tersenyum, menangis, sedih, kaget, dan lain sebagainya. Untuk itu dalam pembuatan karakter wajah yang sesuai dengan bentuk wajah asli manusia diperlukan beberapa titik-titik gerakan daripada karakter wajah tersebut. Kemudian disetiap titik gerakan diberikan 3D axis agar dapat digerakan kesegala arah, sehingga didapatkan gerakan yang sesuai dengan wajah asli manusia.

\section{DAFTAR PUSTAKA}

[1] Arikunto, Suharsimi. 2013. Prosedur Penelitian. Jakarta: PT. Rineka Cipta. Soeheman, Bonnie. 2010. Membuat Sendiri Klip Animasi Multimedia. Jakarta, PT. Elex Media Komputindo

[2] Suyanto, M, 2003. Multimedia Alat Untuk Meningkatkan keunggulam Bersaing. Yogyakarta, Andi Offset.

[3] Arum, Nimas. 2012. Modelling dan Rigging Karakter Film Animasi 3 Dimensi Tentang Proses Pembuatan Tempe. Tugas Akhir. Jurusan Game Animasi, Fakultas Sastra, Universitas Negeri Malang

[4] Effendy, Heru, 2002. Mari Membuat Film panduan menjadi produser, Yogya, Panduan.

[5] Satriawan, Aski. Apriyani, Meyti Eka. 2016. Analisis dan pembuatan rigging karakter 3d pada animasi 3d "Jangan Bohong Dong”. Jurnal Teknik Informatika Vol.9 No.1. UIN Jakarta.

[6] Ludovic, Dutreve. Meyer, Alexander. Orvalho, Veronica. Bouakaz, Saida. 2010. Easy Rigging of Face by Automatic Registration and Transfer of Skinning Parameters. Instituto de Telecomunicacoes. Faculdade de Cincias da Universidade do Porto, Portugal.

[7] Setiadi, 2007, Anatomi dan Fisiologi Manusia, Penerbit Graha Ilmu, Yogyakarta

[8] Rohman, Abdur. 2013. Modelling dan Rigging Karakter untuk Film Animasi 3 Dimensi tentang Harimau Sumatera. Tugas Akhir. Jurusan Game Animasi, Fakultas Sastra, Universitas Negeri Malang.

[9] Djalle, Zaharuddin G., 2006, The Making of 3D Animation Movie, Penerbit Informatika, Bandung

[10] Ioannis A. Kakadiaris; Dimitris Metaxas, 1996, Model-Based Estimation of 3D Human Motion with Occlusion Based on Active Multi-Viewpoint Selection, Department of Computer and Information Science University of Pennsylvania, Philadelphia, PA 1910 